call for the adoption of a British policy in this matter, and the Public Health Laboratory Service has since been engaged in systematic study of different methods, the findings of which are awaited with interest.

1 W.H.O. Expert Committee on Standardization of Methods for Conducting Microbic Sensitivity Tests. World Health Organization Technical Report Series No. 210. 1961.

2 British Medical fournal, 1971, 2, 416.

3 Ericsson, H. M., and Sherris, J. C., Acta Pathologica et Microbiologica Scandinavica, 1971, Supplement No. 217.

4 Bauer, A. W., Kirby, W. M. M., Sherris, J. C., and Turck, M., American fournal of Clinical Pathology, 1966, 45, 493.

Journal of Clinical Pathology,
Federal Register, 1972, Title 37, 20525.

6 Bach, M. C., Zinner, S. H., Wilcox, C., and Finland, M., fournal of Laboratory and Clinical Medicine, 1972, 79, 316.

7 Bach, M. C., Gold, O., and Finland, M., fournal of Laboratory and Clinical Medicine, 1973, 81, 787.

${ }^{8}$ Seneca, H., American fournal of the Medical Sciences, 1973, 266, 381.

Wallick, H., and Hendlin, D., Antimicrobial Agents and Chemotherapy, 1974 , 5,25 .

10 Washington, J. A., Hall, M. M., Fausch, C. J., and Brackin, K. L., Mayo Clinic Proceedings, 1973, 48, 718.

11 Barry, A. L., and Hoeprich, P. D., Antimicrobial Agents and Chemotherapy, $1973,4,354$

12 Advisory Committee on Medical Laboratory Technology, fournal of Medical Laboratory Technology, 1960, 17, 133.

13 Association of Clinical Pathologists, Fournal of Clinical Pathology, 1965, 18,1 .

${ }^{14}$ College of Pathologists of Australia, Medical fournal of Australia, 1968, 2, 171 .

${ }^{15}$ Beaney, N., Goodwin, N. G., Jones, R. V. Winter, R., and Sippe, G. R., Medical fournal of Australia, 1970, 1, 483.

${ }^{6}$ Garrod, L. P., and Waterworth, P. M., Fournal of Clinical Pathology, 1971, 24, 779 . 17 Garrod, L. P., and Waterworth, P. M., Fournal of Clinical Pathology, 1969,

18 Duncan, I. B. R., Antimicrobial Agents and Chemotherapy, 1974, 5, 9.

19 Stokes, E. J., Clinical Bacteriology, 3rd edn., London, Arnold, p. 179, 1968.

20 Brown, D. F. J., and Selkon, J. B., British Medical fournal, 1974, 1, 573.

\section{Thymic Hormones}

The thymus gland seems to secrete two "hormones." Thymin is the name given to the extract from normal thymus that is concerned in the regulation of neuromuscular transmission; it has been shown to reduce the release of acetylcholine at nerve endings. ${ }^{1}$ The serum of myasthenic patients also contains a substance that inhibits acetylcholine synthesis due to a direct action on the enzyme choline acetylase, ${ }^{2}$ and it is tempting to speculate that this hormonal substance is identical with that in the thymic extract.

Recent interest in the thymus has been more concerned with its immunological role. Mice lose their natural immune responses if the thymus is removed just after birth. Ever since Miller showed ${ }^{3}$ that immunological function could be restored to these mice by thymus grafts enclosed in a millipore chamber impermeable to cells, it has been suspected that hormonal factors from the thymus might play a role in the maintenance of immunological function. It was later shown that acellular thymic extracts obtained from the calf could also restore immunological function to thymectomized mice, ${ }^{4}$ and the name thymosin was given to this "hormone."

Small lymphocytes, though superficially identical in appearance, are functionally heterogeneous. Some lymphocytes depend on the thymus for their development ( $T$ cells), while others can reach full maturity without thymic influence (B cells). The differentiation of $\mathrm{T}$ cells is associated with the acquisition of certain antigens on the cell surface, in particular the TL and the theta antigens. The presence of either of these antigens means that the cell has undergone thymus-directed differentiation. ${ }^{6}$ This feature not only permits the ready identification of $\mathrm{T}$ cells but it also provides a basis for assayir $\mathrm{g}$ the thymic hormone. Komuro and Boyse ${ }^{6}$ have shown that a partially purified thymic extract induces precursor cells from the bone marrow of the mouse to acquire these specific antigens indicative of $\mathrm{T}$ cell competence.

Studies on the identification and assay of thymic hormone have been reported recently from Paris by Bach and his colleagues. $^{7}$ They used a test which depends on enumerating cells that form rosettes with sheep erythrocytes in vitro as a means of recognizing $\mathrm{T}$ cell differentiation, ${ }^{8}$ and have identified the hormone in the serum of mice. The hormone disappears after thymectomy and reappears after thymus transplantation, but not after transplanting other lymphoid organs. ${ }^{9}$ Bach et al. have also shown that the thymic hormone is present in human serum. ${ }^{10}$ The serum level is higher in children than in adults; it is not found in subjects over 50 years of age; and the serum level is normal in young patients with myasthenia gravis but does not decrease with age in myasthenic patients as it does in normal individuals. The thymic hormone does, however, disappear in myasthenic patients after thymectomy. Bach et al. have attempted to isolate the thymic hormone from extracts of thymus gland, and they suggest ${ }^{11}$ that it is a peptide with a molecular weight of about 1,000 .

A knowledge of the mechanism whereby the thymus induces precursor cells to become immunologically competent $T$ lymphocytes is of fundamental importance to our understanding of the immune process, and it will provide exciting therapeutic possibilities for the treatment of immune deficiency states. Bach ${ }^{8}$ recently suggested that the high concentrations of hormone within the thymus promote the development of stem cells into $T$ lymphocytes, and that the lower concentrations of hormone in the circulation may be necessary for the extrathymic maturation of $\mathrm{T}$ cells. It is now apparent that we must think of the development of the lymphoid system not only through the seeding from the thymus of stem cells that have differentiated into $T$ cells within the gland but also in relation to humoral products or hormones of the thymus that act on lymphoid tissue outside it.

\footnotetext{
1 Goldstein, G., and Hofmann, W. W., Clinical and Experimental Immunology, 1969, 4, 181 .

2 Nakao, K., and Wada, F., Medical Fournal of Osaka University, 1968 , $19,41$.

3 Osoba, D., and Miller, J. F. A. P., Nature, 1963, 199, 653.

Trainin, N., and Small, M., fournal of Experimental Medicine, 1970, 132, 885.

5 Goldstein, A. L., et al., Proceedings of the National Academy of Science the United States of America, 1972, 69, 1800.

6 Komuro, K., and Boyse, E. A., Lancet, 1973, 1, 740.

7 Bach, J. F., Dardenne, M., and Bach, M.-A., Presse Médicale, 1974, 3, 575.

8 Bach, J. F., Lancet, 1973, 1, 1320.

9 Bach, J. F., and Dardenne, M., Transplantation Proceedings, 1972, 4, 345.

$10 \mathrm{Bach}, \mathrm{J}$. F., et al., Lancet, 1972, 11, 1056.

11 Bach, J. F., Presse Médicale, 1974, 3, 571.
}

\section{Contact Tracing}

The continuing increase in the number of patients with sexually transmitted infections together with the greater ease of travel both at home and abroad have increased the volume, scope, and complexity of contact tracing. Furthermore, the interviewing of patients to obtain the necessary information and to persuade them to help in tracing their own contacts is very time-consuming and cannot be done satisfactorily by busy doctors, already hard-pressed in the clinics. Over the years this work has been increasingly delegated to contact tracers, made available by medical officers of health, who have worked at the clinics under the supervision of the physicians-in-charge. In the early years there was little uniformity in the methods used, in the staff available, or in 
the training of recruits. Gradually, however, improvements have occurred and a group of dedicated, hard-working, and efficient contact tracers has now been established in England and Wales.

There are, however, serious problems with recruitment, training, status, pay, conditions of work, and career prospects. These problems have been highlighted by the recent reorganization of the N.H.S., in which contact tracers are now employed by the area health boards and will be seconded to the clinics for sexually transmitted diseases, where they will work under the direct supervision of the physician-in-charge.

These workers have their own society, the Society of Social Workers in Venereal Diseases, which holds an annual conference. A recent meeting of the society agreed to recommend to the Department of Health that the best name for contact tracers is "social health workers"; it also called for better standards of training and pay. Both status and remuneration have been unsatisfactory in the past. Recruits for this exacting work come from the ranks of health visitors, nurses, social workers, sociologists, and those without any formal training. The most important qualities are the personality of the recruit and her ability to form a good rapport with patients; but qualifications and training are important if a satisfactory career structure is to be developed.

A recent report of a joint subcommittee on sexually transmitted diseases of the Scottish Home and Health Department and the Scottish Health Services Council ${ }^{1}$ drew attention to the importance of contact tracing in controlling the spread of these diseases. It stressed the urgent need for recruitment and to provide a career structure and suitable in-service training programmes. Meanwhile in England research into several aspects of contact tracing is being promoted by the Health Education Council and Department of Health and Social Security. Contact tracing can be both interesting and rewarding and, provided a suitable career structure and satisfactory standards of pay can be established, the prospects for those taking up this work are excellent. The opportunity provided by reorganization of the N.H.S. to achieve these aims should not be allowed to drift by.

1 Scottish Home and Health Department, Scottish Health Services Council, Sexually Transmitted Diseases. 1974. H.M.S.O. 29p.

\section{Infection and Diabetes}

An infection in a diabetic can upset blood glucose control and lead to symptoms, even to the extent of precipitating ketosis. Infections may therefore be more of a nuisance to diabetics than to the rest of the population and cause more problems for their doctors-but are they more prone to infection? In the past they most certainly were. Before the advent of insulin therapy, infection was a major cause of death among diabetics and, among the infections, tuberculosis was the leader. As recently as the 1950s reports were still appearing of excess mortality or more florid and rapidly progressive tuberculosis among diabetics, though the disparity between them and non-diabetics was diminishing. ${ }^{1}$ However, diabetics have shared in the decline in tuberculosis in most countries.

There are certainly special circumstances affecting the diabetic which may predispose to infection. Pruritus vulvae and less often balanitis in the male are associated with candidial infections; this may possibly be due to heavy glycosuria or the increased glucose content of the secretions of the genital tract favouring the growth of the organisms. If bladder emptying is impaired by autonomic neuropathy the chronic retention of urine predisposes to urinary tract infection. Catheterization, too, is now recognized as a source of infection ${ }^{2}$; but in the absence of a history of catheterization (or other instrumentation) or autonomic neuropathy it seems that the diabetic is no more prone to urinary infection than the non-diabetic. ${ }^{34}$ The excess of pyelonephritis in post-mortem or biopsy studies of kidneys of diabetics is now regarded as evidence of vascular disease and not of infection. Necrotizing papillitis is traditionally associated with the diabetic, but is now a rare event and is more likely to be associated with abuse of phenacetin. The most common site of infection in diabetics is the feet of patients, usually elderly, with peripheral neuropathy, arterial insufficiency, or a combination of the two. ${ }^{5}$

Apart from these special circumstances, the evidence that diabetics-at least in our relatively hygienic society-are more prone to infection is fragmentary. Diabetics do who acquire infections may well present therapeutic problems because of associated loss of control or because of slower response to chemotherapy or antibiotics. Some abnormality of the natural defence against infection has long been suspected and sought in the diabetic. In general, humoral factors have not been found abnormal, but recently evidence has been found of cellular abnormalities. In 1964 Bybee and Rogers ${ }^{6}$ showed that phagocytosis was impaired in ketotic diabetics, and later Bagdade et al. made similar observations on whole blood from patients with hyperglycaemia but without ketoacidosis. This defect in phagocytosis disappeared after insulin therapy. Mowat and Baum ${ }^{8}$ reported that migration of polymorphonuclear leucocytes was delayed in the diabetic, and Bagdade et al. have now reported ${ }^{9}$ further investigations. They studied patients with poor control but without ketoacidosis, and confirmed that there was impaired phagocytosis in their serum and that this was restored towards normal with hypoglycaemic therapy. Serum from the diabetics also reduced phagocytosis by control granulocytes, while serum from controls improved phagocytosis by diabetics' granulocytes. Furthermore, dilution of diabetics' serum reduced the inhibitory effect on control granulocytes, while addition of glucose to normal serum resulted in inhibition of normal granulocytes, suggesting that hyperglycaemia itself may determine the change in granulocyte function. Certainly, glucose metabolism is important in the granulocyte ${ }^{10}$ and a few minutes after the start of phagocytosis, cell respiration suddenly increases. ${ }^{11}$

In The Doctor's Dilemma Shaw had Sir Ralph BloomfieldBonington say "There is at bottom only one genuinely scientific treatment for all diseases ... Stimulate the phagocytes." Perhaps the injunction for diabetics should be to disinhibit the phagocytes by effectively lowering the blood sugar.

1 Younger, D., and Hadley, W. B., In Foslin's Diabetes Mellitus, 11th edition. ed. A. Marble et al., Philadelphia, Lea and Febiger, 1971.

2 Vejlsgaard, R., Acta Medica Scandinavica, 1966, 179, 173.

3 Pometta, D., et al., New England fournal of Medicine, 1967, 276, 1118

4 O'Sullivan, D. J., et al., British Medical fournal, 1961, 1, 786.

5 Catterall, R. C. F., British Fournal of Hospital Medicine, 1972, 7, 224.

Bybee, J. D., and Rogers, D. E., Fournal of Laboratory and Clinical Medicine, 1964, 64, 1 .

7 Bagdade, J. D., Nielson, K. L., and Bulger, R. J., American fournal of Medical Sciences, 1972, 263, 451.

8 Mowat, A. G., and Baum, J., New England fournal of Medicine, 1971

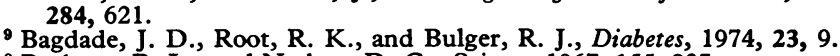

10 Baehner, R. L., and Nathan, D. G., Science, 1967, 155, 835.

11 Klebanoff, S. J., Annual Review of Medicine, 1971, 22, 39. 